\section{Neuropsicologia Hoje}

Vivian Maria Andrade, Flavia Heloisa dos Santos e Orlando F. A. Bueno

A história da neuropsicologia no Brasil é relativamente recente e, como conseqüência, a produção científica vem sendo acumulada somente nos últimos anos. A obra Neuropsicologia Hoje é um exemplo deste cenário, onde a experiência dos autores é descrita em campos de atuação específicos. O texto é estruturado em quatro seções: I Conceitos Gerais; II - Infantil; III - Adulto; IV - Idoso.

Em Conceitos Gerais, composto por nove capítulos, o livro aborda os aspectos históricos da neuropsicologia, as bases estruturais do sistema nervoso e algumas funções cognitivas, incluindo inteligência, atenção, funções executivas, memória e linguagem. Na seção Infantil, quatro capítulos abrangem a neuropsicologia do desenvolvimento, a memória operacional e estratégias de memória, a avaliação neuropsicológica infantil e a reabilitação cognitiva pediátrica. Em Adulto, os sete capítulos referem-se a temas relacionados à epilepsia, à avaliação neuropsicológica em traumatismo craniencefálico, à reabilitação neuropsicológica em lesão cerebral adquirida, a aspectos cognitivos da esclerose múltipla, à reabilitação: um modelo de atendimento interdisciplinar em esclerose múltipla, à doença de Parkinson: aspectos neuropsicológicos, e a aspectos neuropsicológicos associados ao uso de cocaína. Finalmente, em Idoso, três capítulos abordam o envelhecimento e memória, a avaliação e reabilitação neuropsicológica no idoso e a redução da assimetria hemisférica em adultos mais velhos: o modelo Harold.

O livro possui o grande mérito de se destacar entre as obras pioneiras na área de neuropsicologia publicadas no Brasil. Sua contribuição é de extremo valor aos estudantes de graduação e profissionais que estão iniciando suas atividades neste campo. Entretanto, a tentativa de apresentar um conteúdo voltado a pratica clínica e pesquisa, simultaneamente, é uma tarefa árdua e, na maioria das vezes, difícil de ser atingida de maneira satisfatória. Embora os autores tenham se esforçado em apresentar um conteúdo atualizado, observa-se, em algumas ocasiões, ausência de sistematização e análise crítica dos tópicos apresentados. Entre alguns aspectos polêmicos relacionados a este campo, encontram-se a escassez de instrumentos fidedignos que avaliem os resultados das técnicas de reabilitação cognitiva e neuropsicológica ('outcome measures') e estudos científicos controlados comparando a eficácia das diferentes técnicas de tratamento.

O crescente número de publicações e de métodos inovadores de investigação, como as técnicas de neuroimagem, torna cada vez mais difícil a tarefa de atualizar profissionais deste campo através de uma única obra. Apesar disso, o livro aborda alguns dos principais temas da atualidade na área de neuroimagem, de maneira brilhante, através do capítulo "Redução da assimetria hemisférica em adultos mais velhos: o modelo Harold", por exemplo.
Para concluir, vale ressaltar a importante contribuição de todos os autores neste empreendimento desafiador, acrescida de pesquisas realizadas pelos mesmos, demonstrando que no Brasil este campo vem se consolidando não somente na área clínica, mas também científica e acadêmica.

\section{Eliane Correa Miotto}

Departamento de Neurologia

Hospital das Clínicas da Faculdade de Medicina da Universidade de São Paulo

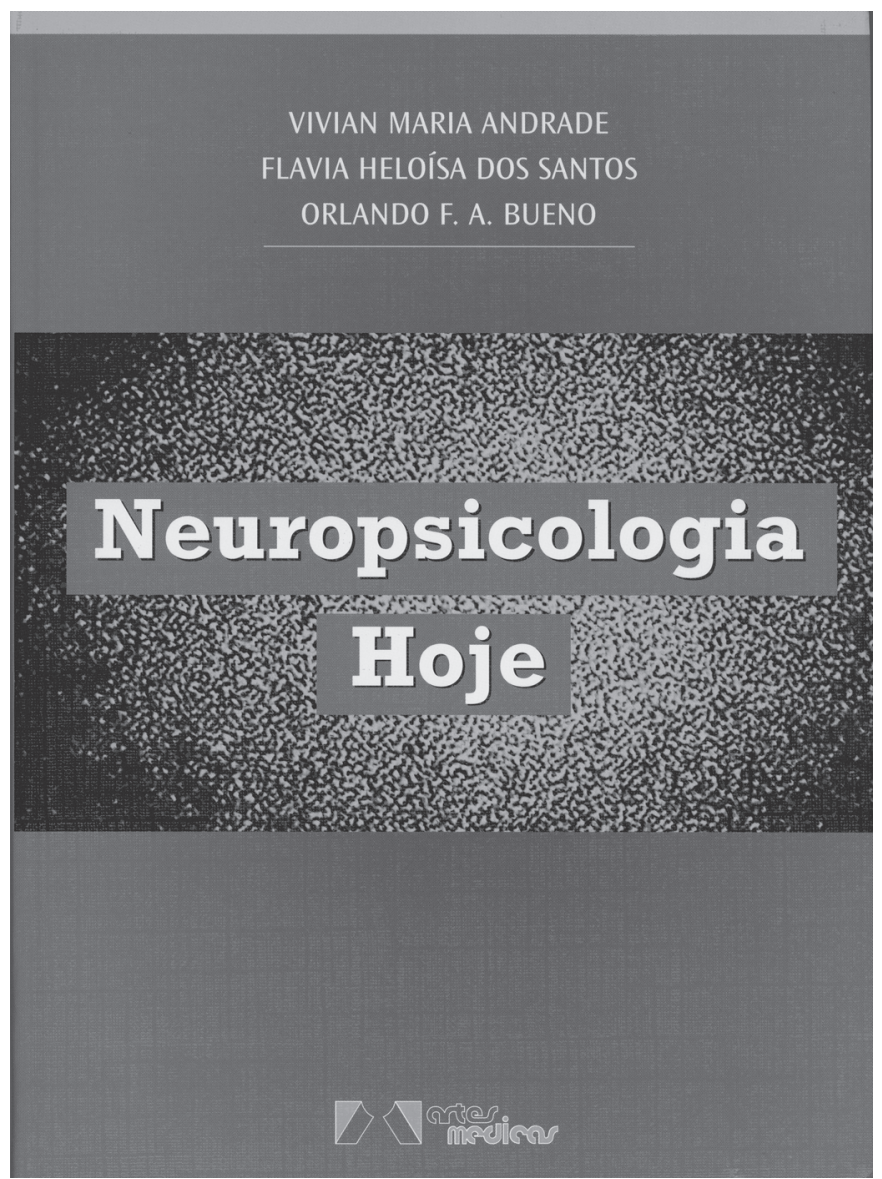

